\title{
Ectopic Renin Secretion Syndrome
}

National Cancer Institute

\section{Source}

National Cancer Institute. Ectopic Renin Secretion Syndrome. NCI Thesaurus. Code C8439.

A syndrome characterized by abnormal secretion of renin in conjunction with neoplastic growth occurring anywhere in the body. 